\title{
Feasibility of Mobile Mental Wellness Training for Older Adults
}

Heidi Similäa,b, Milla Immonen ${ }^{a, b}$, Jaana Toska-Tervolac, Heidi Enwald ${ }^{d, e, f}$, Niina Keränen,e, Maarit Kangas ${ }^{\mathrm{g}, \mathrm{e}}$, Timo Jämsäg,e,h, Raija Korpelainen ${ }^{\mathrm{b}, \mathrm{i}, \mathrm{e}}$

a VTT Technical Research Centre of Finland Ltd, Kaitoväylä 1, P.O. Box 1100, FI-90571 OULU, Finland ${ }^{b}$ Center for Life Course Health Research, University of Oulu, P.O. Box 5000, 90014 Oulu, Finland 'Social and Health Services, Elderly Care, City of Oulu, Myllytie 4, 90500 Oulu, Finland

${ }^{d}$ Information Studies, Faculty of Humanities, University of Oulu, P.O. Box 8000, 90014 Oulu, Finland e Medical Research Center Oulu, Oulu University Hospital and University of Oulu, P.O. Box 5000, 90014 Oulu, Finland

${ }^{\mathrm{f}}$ Information Studies, School of Business and Economics, Åbo Akademi University, Fänriksgatan 3 B, 20500 Turku, Finland

${ }^{\mathrm{g}}$ Research Unit of Medical Imaging, Physics and Technology (MIPT), University of Oulu, P.O. Box 5000, 90014 Oulu, Finland

${ }^{\mathrm{h}}$ Department of Diagnostic Radiology, Oulu University Hospital, 90220 Oulu, Finland

'Oulu Deaconess Institute, Department of Sports and Exercise Medicine

\section{Corresponding author}

Heidi Similä

VTT Technical Research Centre of Finland Ltd

Kaitoväylä 1, P.O. Box 1100, FI-90571 OULU, Finland

Mobile +358 405079378

heidi.simila@vtt.fi 


\section{Acknowledgements}

This study was part of the Gamified remote service concept for promoting health of older people (GASEL) project funded by Tekes - the Finnish Funding Agency for Innovation.

We thank MA Kirsi Korhonen and MA Merja Tuomaala for performing the observational study, and Kaisa Nurmi from City of Oulu for her participation and valuable comments throughout the study. We would also like to thank Jaakko Tornberg from ODL and Salla Muuraiskangas from VTT for their help in designing and organizing the study. 


\begin{abstract}
Mobile technology has been increasingly adopted in promotion of mental health among older people. This study assessed the feasibility of a mobile mental wellness training application for individual use and for group work from the perspectives of older adults and social care professionals. The older individuals recruited for the study were participants in a Circle of Friends group and family caregivers' peer support group offered by the communal senior services. The qualitative and quantitative results of interviews, questionnaires, observation, and application usage were reported. Seven older adults started using the application independently at home in parallel with the group activity. This study revealed new information regarding the barriers to the older adults' full adoption of such mobile technologies. The results indicated that there may be potential in the incorporation of mobile technologies in promotion of mental health of older people at group settings.
\end{abstract}

Keywords: Depression, acceptance and commitment therapy, mobile phone, mHealth, group intervention, older adults 


\section{Introduction}

Mental health disorders, such as depression, are significant problems among older adults. The global prevalence of depression in older adults is estimated to be $5-20 \%$, depending on cultural context. ${ }^{1}$ According to World Health Organisation (WHO), unipolar depression occurs in $7 \%$ of the general older population and approximately $15 \%$ of adults aged 60 and over suffer from a mental disorder. ${ }^{2}$ The global population is ageing rapidly and between 2015 and 2050 , the proportion of the world's population over 60 years will nearly double, from $12 \%$ to $22 \%$, and the mental health care resources will struggle to provide help and prevention for older adults suffering from depression. Mental health also has an impact on physical wellness and vice versa. Caring and preventing mental disorders is important also from the point of supporting independent living and functional capability of older adults. Prevalence of mental health disorders is twice as high among home care patients, according to some reports, even up to $62 \% .^{3}$ The prevalence of mental health disorders has shown to be increasing and, for example in Finland, $11.5 \%$ of people aged 65 years or older were prescribed antidepressants (compared to $9.4 \%$ of people aged $25-64$ years) in $2014 .{ }^{4}$ Depression is highly correlated with loneliness, ${ }^{5}$ and a similar proportion of Finnish persons aged 75 years or older felt alone either fairly often or all the time. ${ }^{6}$ Depressive disorders are associated with greater morbidity and mortality in general, while subjective well-being is associated with the increased survival of older individuals. ${ }^{7}$ Generally speaking, worldwide interest in the promotion of mental wellbeing has arisen as measurements of well-being have been adopted as key economic indicators alongside gross domestic product (GDP). ${ }^{8}$

Mobile health (mHealth) has been presented as a new frontier for the delivery of mental health treatment. ${ }^{9}$ Mobile mental health or mental mHealth can be defined as the application 
of mobile phones to mental health practice. Advantages include interactivity, just-in-time delivery, low resource requirements, and portability. ${ }^{10}$ The effects of mental health mobile apps on mental health have been evaluated. ${ }^{11,12}$ The reviews concluded that mental health apps may be effective and improve the accessibility of treatment. However, many of the available mental health applications were not based on scientific evidence. ${ }^{12}$

The IMS Institute for Healthcare Informatics identified 712 mental health apps for Apple iOS and Google app platforms in $2015 .^{13}$ Due to the older population's lower use of information and communications technology (ICT) and the specific usability challenges that age-related changes pose, ${ }^{14}$ adapting mHealth for seniors is not straightforward. However, the use of information technologies among older age groups is increasing. In Finland, 93\% of the total population and $70 \%$ of the population aged $65-74$ years have used the Internet within the previous 12 months. ${ }^{15}$ Moreover, sixty-nine percent of the total population and $28 \%$ of the older population had used the Internet with a mobile device. ${ }^{16}$ The mobile phone usage rate was nearly $90 \%$ in all age groups in $2013 .{ }^{17}$ The ability to reach the most vulnerable population groups, such as older adults, is one of the five main categories of barriers that healthcare providers have listed regarding mHealth apps. ${ }^{13}$

Growing interest in mindfulness techniques that focus on paying intentional and nonjudgemental attention in the present moment has resulted in growing number of mobile applications based on those techniques. Although some recent studies on their usefulness exist, $^{18,19}$ the evidence is scanty and more studies are needed. ${ }^{20}$ There are no studies evaluating the feasibility of these applications for older populations. A web-based acceptance and commitment therapy $(\mathrm{ACT})^{21}$ intervention was found to be acceptable to clients and to have positive impact on depressive symptoms, psychological flexibility and mindfulness 
skills. ${ }^{22}$ The study suggests that web based ACT-interventions are useful as an early-stage intervention. Oiva is a mobile mental wellness training application that is based on $\mathrm{ACT},{ }^{21}$ and its exercises, including mindfulness techniques, are aimed at supporting the active learning of mental wellness skills and increasing psychological flexibility. The application can also be called "positive technology" 23 or defined as an example of mHealth $2.0 .^{24}$ The feasibility of the Oiva mobile application was demonstrated in a one-month field trial with 15 working-age participants. ${ }^{19}$ The stress ratings of the participants decreased and life satisfaction scores increased significantly during the trial. The application showed good acceptability, usefulness, and engagement among the study participants. The applicability of the Oiva application was also evaluated by depression nurse specialist students in Finland. ${ }^{25}$ The results implicate that the Oiva mobile application is a credible, feasible, and useful self-management tool, suitable for use in prevention and treatment of depression and other mental issues. The application seemed beneficial tool in treating mild to moderate symptoms, but only trained professionals should use it with patients who have severe problems such as psychosis or schizophrenia. However, before this study the feasibility of the Oiva application has not been tested among older adults.

The main focus of this pilot study was to assess the feasibility of a mobile mental wellness training application for older adults. The study investigated the usage, usability, acceptance, and usefulness of the application, and its impact on depressive symptoms and mindfulness skills of older adults. Furthermore, the aim was to assess the suitability of the application for group activity targeted for older adults. 


\section{Methods}

\section{Study design}

This paper reports a descriptive study that combines qualitative and quantitative methods to examine the feasibility of a mobile mental wellness training application for older adults. A methodological triangulation, where multiple methods are used to study a single problem or phenomenon, ${ }^{26}$ was used to investigate the usage, usability, acceptance, and usefulness of Oiva application. The reception and usage of the mental wellness training application was observed by non-participant observation method during the introductory session. The application was tested by older adults and health care professionals independently at home and as part of group activities. The independent use of the application was monitored by collecting application usage logs. In addition, questionnaires and semi-structured interviews were used to collect data. The study procedure is explained in more detail below.

This study was conducted as part of a larger population based Gamified remote service concept for promoting health of older people (GASEL) study that was aimed at deriving requirement specifications for a holistic well-being service for older adults. The Ethics Committee of Human Sciences at the University of Oulu (statement 6/2014) approved the GASEL study protocol. All participants received oral and written information about the study and signed informed consent forms.

\section{Study participants}

The older adults were recruited for this study from two groups: a Circle of Friends group and a peer support group for family caregivers. The groups were offered by the senior services of the City of Oulu and both were led by the same social instructor and occupational therapist. 
The Circle of Friends group was based on the Circle of Friends model ${ }^{27}$ with aim to prevent and alleviate loneliness among older adults, positively impact their quality of life, empower them, and increase their control over their lives. Subjective experience of one's own survival, loneliness, the need for help, and satisfaction with social relationships affected admittance to the group. In addition, the inclusion criteria for the Circle of Friends group was a score of six on the Geriatric Depression Scale (GDS-15), ${ }^{28}$ a threshold commonly used to indicate depression in older adults. ${ }^{29}$ The group was organized once a week for 12 weeks. Each session had a theme, e.g. mood or loneliness, that was selected by the group leaders based on participants' needs. The group had five participants, of whom four consented to this study.

The peer support group for family caregivers was targeted for older family caregivers, who took care of their family members daily. The main objective was to share experiences of daily life, feelings, information and guidance between peers. The group gathered once a week for three months. It had eight participants of whom three consented to this study. Thus, there were seven older adult participants in total and two health care professionals, i.e. the group leaders, who took part in this study.

\section{Oiva application}

Oiva is a stand-alone mobile application for mental wellness training designed cooperatively by experts in psychology, technology, and users. The application has four intervention paths with a total of 46 text and audio exercises and an introductory video for each path. The exercises comprise an ACT-based ${ }^{21}$ intervention program with the following topics: "Aware Mind", "Wise Mind", "Values", and "Healthy Body". Each exercise lasts about 1-3 minutes and one can listen to it or read it as a text. The application suggests the order of the exercises, but the user is also free to follow an order of his or her choice. The user can also add his or her 
favourite exercises to a list, enabling quick access from the main view. A more detailed description of the functionalities and content has been published previously. ${ }^{19}$ The application saves the date and time when it starts as well as information regarding the user's navigation. For example, the starting times of each exercise session are stored in the usage log. The application language is Finnish.

The ZTE Skate Android mobile phone was provided to the test users. It had a 4.3-inch touchscreen, and the users were able to listen to the exercises with the accompanying earphones. The usage logs that the Oiva application recorded were collected from the devices after the testing.

\section{Study procedure}

In the Circle of Friends group, the Oiva application testing was incorporated as part of group activities, meaning the study participants were exposed to both normal group intervention and mobile mental wellness training. Although, participation to mobile application testing was voluntary and some of the group members did not take part in this study. The social instructor and occupational therapist leading the group first introduced the research project to the group participants and inquired about their initial willingness to participate in testing the mobile application. The researchers participated in one group session, where they introduced the research project in general and the Oiva application, and guided through its basic functionalities. The group participants tried the mobile application by themselves for approximately 15 minutes and then decided whether to take part in the study. The introductory session was observed by two master's degree students from Information Studies. They used the structured non-participant observation method. That is, they did not participate in what was happening in the social setting, the issues to be observed had been 
decided beforehand, and an observation schedule had been made in advance for taking notes. ${ }^{30}$ The factors observed were answering, hesitating, accepting, and commitment to use the Oiva application. Also, the fluency of use and different emotions were observed.

Those who agreed to participate in the study were given a mobile device with an Oiva application, which each of them could use independently at home in between the group sessions. Furthermore, the group leaders incorporated some of its exercises into the group activities. During the first few sessions the group leaders instructed the participants in using the mobile devices, and the participants used their devices to watch the exercises. Later, the group leaders started to show the same exercises using a TV screen to better facilitate mutual and shared experiences among the participants, also for those not taking part in this study. The study participants were able to continue using the mobile devices independently between the sessions. The group leaders selected the exercises separately for each session. The topics of the groups were related to mood and loneliness, and they were specified according to the needs of the participants. Typically, two exercises were included in each session. After the exercise, the group reviewed the experience through discussion.

For the family caregivers, the study and the application were introduced by the group leaders during one of the group sessions. Otherwise the application use was not included in their group activity and the family caregivers tested the application independently at home in between their group sessions. The group leaders collected the consents from the study participants and handed out the mobile devices for the testing.

\section{Data collection}


At the beginning, all the study participants filled in a baseline questionnaire about demographics, their social networks, interests, experienced health, moods, sense of purposefulness, prior use of technology, and expectations and motivation regarding the study. Depressive symptoms were assessed with the Geriatric Depression Scale (GDS-15) ${ }^{28}$ and mindfulness skills of the participants were measured using the Freiburg Mindfulness Inventory (FMI). ${ }^{31}$ The GDS-15 and FMI measurements were repeated the end of the group work as part of a final questionnaire. The questionnaire addressed the usage of the Oiva application. It asked about the perceived usefulness of the application topics, the location and time of use of the application, how the exercises were performed, which exercises were preferred and which were not considered suitable. The questionnaire also asked how Oiva was perceived in general, whether it had an effect on well-being, any further comments or development ideas, and the experiences of participating in the study in general.

The family caregivers were invited to an unstructured feedback session with a researcher, and they were able to reflect their experiences with each other and to give verbal feedback about the application and testing procedure.

The group leaders, i.e. the social instructor and occupational therapist, were interviewed by a researcher through a semi-structured interview. The interview addressed the following topics; background information of group leaders (profession, work experience, etc.), prior use of technology as part of daily work, user experience of the Oiva application (usefulness, ease of use, was it easy to take into use, etc.), how they incorporated the application in group activities, whether they would continue using it after the study, have they used it to support their own wellbeing, what were the most useful features and exercises, who would benefit from the application the most, were there any problems during the use, and how current 
working methods support the application of new technologies. In addition, all the comments and feedback they gave throughout the study in face-to-face meetings and via email were collected for later use.

\section{Data analysis}

The Oiva application usage logs collected from mobile phones were analyzed to determine how often and for how long each participant used the application during the study. Associations of prior use of ICT, expected usefulness, and ease of use of mobile ICT were evaluated against Oiva application usage time. The depressive symptoms (GDS-15) and mindfulness skills (FMI) evaluated at baseline and after the study were compared. Two student observers consolidated their notes for mutual understanding and analysis of the introductory session. The qualitative data, collected through introductory session notes, questionnaires, interviews, and in the feedback session, were analyzed by qualitative content analysis according to the themes of acceptance, usefulness, and usability of the application. 


\section{Results}

\section{Usage}

Seven women (mean age: 73 years, SD: 7.0 years, range: $66-82$ years) participated in this study. Four of them were members of Circle of Friends group and three were from family caregivers group. Five participants had Internet access at home and four had used a computer within the previous 12 months; only one had used a smartphone or tablet. Two had not used any of these. Table I presents the participants' use of the Oiva application.

Table I. Usage of Oiva application

\begin{tabular}{|c|c|c|c|c|c|c|c|c|c|}
\hline ID & $\begin{array}{l}\text { Group } \\
\begin{array}{c}\mathrm{C}=\text { Circle } \\
\text { of }\end{array} \\
\text { Friends, } \mathrm{F} \\
=\text { Family } \\
\text { caregivers }\end{array}$ & $\begin{array}{c}\text { Days in } \\
\text { use } \\
\text { (device) }\end{array}$ & $\begin{array}{l}\text { Total } \\
\text { number } \\
\text { of } \\
\text { sessions }\end{array}$ & $\begin{array}{c}\text { Total } \\
\text { number } \\
\text { of } \\
\text { usage } \\
\text { days }\end{array}$ & $\begin{array}{c}\text { Max } \\
\text { sessions } \\
\text { /day }\end{array}$ & $\begin{array}{c}\text { Mean } \\
\text { duration } \\
\text { of } \\
\text { sessions } \\
\text { [min] }\end{array}$ & $\begin{array}{c}\text { Min } \\
\text { duration } \\
\text { of } \\
\text { sessions } \\
\text { [min] }\end{array}$ & $\begin{array}{c}\text { Max } \\
\text { duration } \\
\text { of } \\
\text { sessions } \\
\text { [min] }\end{array}$ & $\begin{array}{l}\text { Total usage } \\
\text { time [min] }\end{array}$ \\
\hline 1 & C & 164 & 111 & 65 & 5 & 23.5 & 0.2 & 80.9 & 2610.7 \\
\hline 2 & C & 31 & 13 & 9 & 2 & 17.7 & 0.5 & 41.6 & 229.4 \\
\hline 3 & C & 53 & 26 & 7 & 8 & 6.9 & 0.3 & 39.2 & 180.1 \\
\hline 4 & C & 40 & 18 & 9 & 3 & 13.7 & 0.2 & 33.8 & 246.8 \\
\hline 5 & $F$ & 140 & 21 & 16 & 3 & 17.8 & 0.2 & 90.4 & 373.3 \\
\hline 6 & $\mathrm{~F}$ & 140 & 46 & 28 & 5 & 13.8 & 0.3 & 60.2 & 636.4 \\
\hline
\end{tabular}




\begin{tabular}{|l|l|l|l|l|l|l|l|l|l|}
\hline 7 & $\mathrm{~F}$ & 19 & 5 & 3 & 2 & 23.2 & 0.5 & 65.7 & 115.9 \\
\hline
\end{tabular}

Previous use of ICT, expected usefulness and ease of use of mobile ICT and usage time of Oiva are presented in Table II. Two study participants had no prior experience on Internet, computer, smartphone, or tablet. The other participant used Oiva for less than six hours. However, the other one used Oiva for more than 24 hours, which was the longest time in this study. All three users who ended up using Oiva for a total time of more than six hours had responded positively to the question regarding the possible usefulness of smartphones or tablets in general. 
Table II. Previous use of ICT, expected usefulness and ease of use of mobile ICT and usage time of Oiva among study participants $(n=7)$.

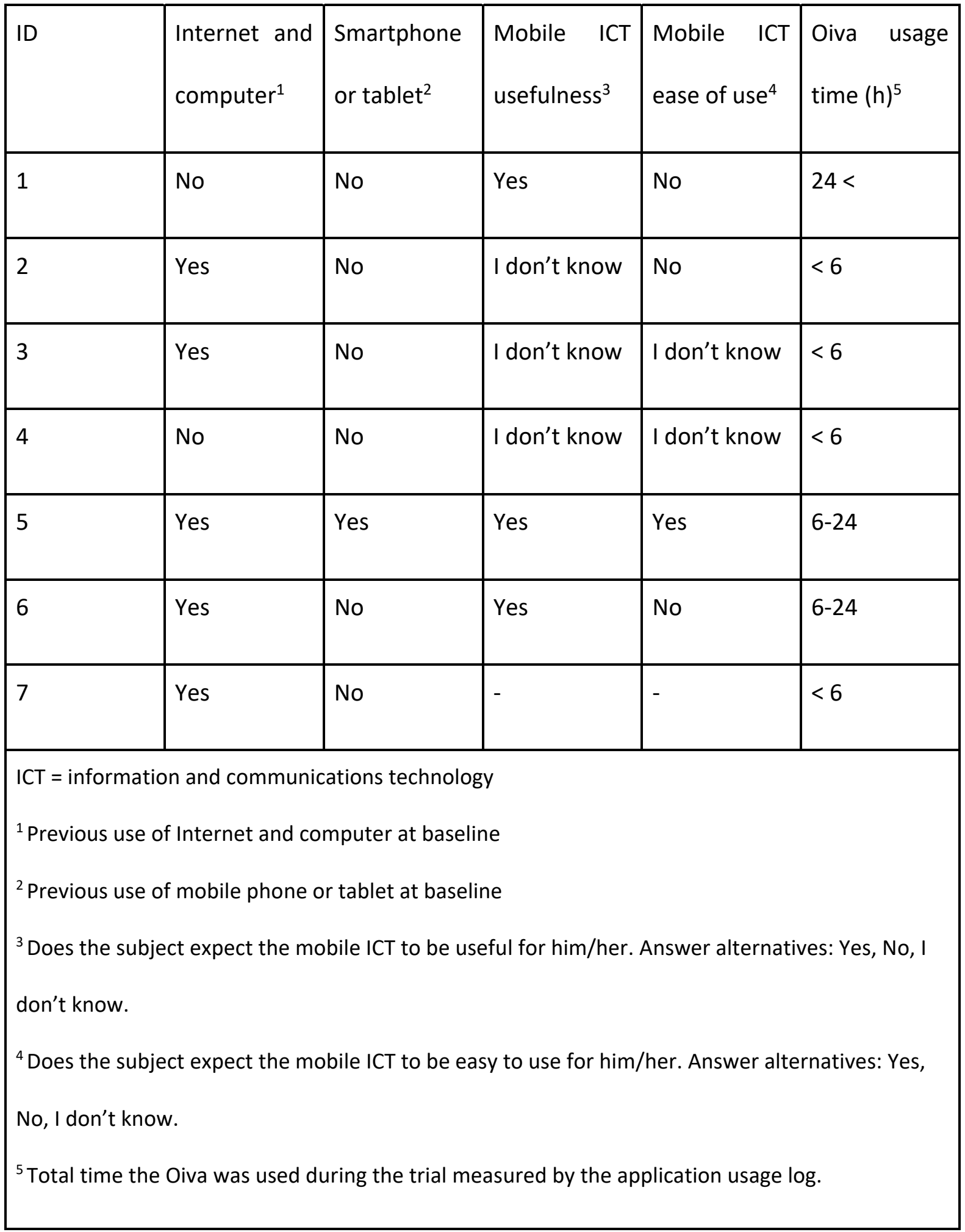

\section{Mindfulness skills and depressive symptoms}


The mindfulness skills and depressive symptoms of the participants were evaluated at baseline and after the trial with FMI and GDS-15 measures (Table III). The FMI and GDS-15 were determined for all the participants at baseline and at the end for four participants that completed the study. Mean FMI scores at baseline was 33.9 (SD: 7.5, range: $25-44$ ) and in final assessment 35.5 (SD: 8.1, range: 28-43). Mean GDS-15 score at baseline was 6.1 (SD: 1.8, range: $4-9)$ and in final assessment 4.8 (SD: 3.3, range $0-7)$.

Table III. Mindfulness skills and depressive symptoms of the participants $(n=7)$ evaluated at baseline and in the final assessment

\begin{tabular}{|l|l|l|l|l|}
\hline ID & Baseline FMI & Final FMI & Baseline GDS-15 & Final GDS-15 \\
\hline 1 & 25 & 29 & 9 & 0 \\
\hline 2 & 28 & 28 & 6 & 7 \\
\hline 3 & 35 & - & 8 & \\
\hline 4 & 36 & - & 6 & \\
\hline 5 & 42 & 43 & 5 & 5 \\
\hline 6 & 44 & 42 & 5 & 7 \\
\hline FMI= Freiburg Mindfulness Inventory 31 GDS-15= Geriatric Depression Scale & \\
\hline
\end{tabular}


One participant perceived Oiva as being very useful and got the opportunity to continue testing the application on her own for three more months. She completed the final questionnaire again after the additional usage period. Her FMI score increased from 29 to 42 points after the independent-use period, indicating improvement in mindfulness skills. Furthermore, the GDS-15 score remained low at 1 point.

\section{Acceptance}

The group leaders (social instructor and occupational therapist) were not familiar with the Oiva application beforehand, but they were highly interested in the opportunity to test it as part of their group activities. The other group leader familiarized herself with the use of mindfulness techniques in the treatment of depression by reading related literature. She expected the application, together with group activities, to help participants feel gracious for themselves and the others, and to learn to accept themselves and their choices better. Her personal experience of the possibilities that Oiva offered was positive. Moreover, she used the application herself during her free time.

The introductory session of Oiva application in the Circle of Friends group was observed to evaluate the acceptance of the application by the test users. Five individuals were present, but one refused to participate in the testing. Hence, there were four test users. All four participants asked questions and needed help when using the application. One of them was keen to learn more, and the other sought confirmation to her thoughts. Two participants hesitated and needed a lot of help, and their attitudes seemed negative, which presumably affected their user experience.

Concerning ease of use, both ends of the scale were apparent: one participant clearly considered the application to be easy to use and even helped others, whereas the other did 
not even attempt to use it without help. Due to difficulties in use, the irritation and frustration of one participant increased during the test situation. Two participants seemed to accept the application and listened to the instructions carefully and the pleasant feelings of one of the two seemed to grow during the test situation.

Four participants from the Circle of Friends group started using the application independently, but two of them used the application only for a short time and finally wanted to withdraw from the study. They also refused to fill in the final questionnaire. In the family caregivers group, thee participants started using the Oiva application. Two of them completed the study and one participant withdrew from the study referring to sleep problems. Hence, there were four participants in total completing the study, two from each group.

\section{Usefulness}

According to the group leaders, the overall user experience of the Oiva application was positive and two older users in particular got help managing their depression and anxiety. They felt that the recognition of user needs contributed to the introduction and acceptance of the application. Regular use and the exercises assisted the older users in their daily lives. The group leaders said the following:

"One of the study participants reported that she now sleeps better and even without sleep medicine. Her thoughts have turned more positive, which has also been noticed by her close ones. Due to this, the relationship with the close ones has become better."

In the final questionnaire, on a scale of 1 to 7 (with 1 meaning "really bad" and 7 meaning "really good"), the Circle of Friends participants gave the Oiva application overall grades of 6 and 3 and family caregivers gave overall grades of 5 and 1 . One person in both of the groups reported learning new skills by using the application. They learned to increase self-knowledge 
and mental well-being, clarify personal values, and live in the moment. The group leaders agreed that the application taught the participants how to be present in the here and now without worrying about the past or fearing the future. They also said:

"The other participant said the regular use has helped with depressive symptoms, which can also be seen in the depression test results. Ability to concentrate has become better and worrying has decreased."

Three out of four respondents found especially the physical exercises the most relevant for them. One subject, who wanted to continue using the application after the study, considered particularly relaxation and breathing exercises useful for alleviating stress. She also valued especially the introductory videos for each topic and pointed out several favourite exercises but also said that some topic areas could have had fewer exercises. The older users indicated that, by regular use, they learned how to apply the exercises in their daily lives without having to listen to the mobile device. This was a particularly important insight according to the group leaders. They considered that the exercises were sufficiently short and easy to remember. Thus, they were easily applicable when necessary, provided that the user did not have a memory disorder. However, they thought some of the Oiva application exercises sounded peculiar at first, and, in some cases, several tries were needed to understand the idea and purpose of the exercises.

The family caregivers considered the concept of the application as good. They valued the application's layout, saying it was good and practical. They suggested that the application was good for depressed people and particularly suitable for those who were not familiar with the associated topics beforehand. However, they commented that the Oiva application was more suitable for a 20 -year-old person than it was for a 70 -year-old person. They felt that the 
current application had too many exercises and it should have offered the possibility of tailoring the content according to personal preferences. They said that it was not very suitable for family caregivers, who had to live in the moment and were not able to concentrate on exercising within everyday life. According to them, family caregivers needed different kinds of help, for instance, peer support groups. The other said that one's own needs always came second to taking care of a family member and that the application was not a solution for that. She also commented:

"For me the human voice is not enough, I need face-to-face contacts and opportunities to share feelings. Fortunately, I have friends and the family caregivers' peer support group!".

It was challenging for the family caregivers to find their own time and space to use the application, and they said that they were not able to concentrate during periods of privacy interspersed with everyday chores. The group leaders suggested that family caregivers would benefit from a more continuous program, for instance, one on a $C D$, which did not require the user to take any actions.

\section{Usability}

The group leaders stated that better information technology skills would have helped application utilisation. It was difficult for participants to learn how to use and perceive the application without prior IT knowledge or with memory disorders. The older participants in the study had to learn how to use both the smartphone and the application. According to the group leaders, more time would have been necessary for the participants to learn how to use the mobile device. The older users complained about the device as well. The sound volume of the phone speakers was considered as excessively low and the earphones did not work properly. The cold winter weather with temperatures below $0{ }^{\circ} \mathrm{C}$ caused problems, as the 
mobile device stopped working. In addition, it was inconvenient that the application required the user to act in order to change the exercise each time.

\section{Discussion}

The present study evaluated the feasibility of a mobile wellness training application for use by older people on an individual basis at home and as part of group activity. The application sparked the interest of professionals (group leaders) and of the older people participating in the groups. They considered the topics of the application exercises to be useful and appropriate for addressing depression. However, we observed that the attitudes and technology skills of the old people could become substantial barriers to individual use and, thus, to the full adoption of the solution.

The initial acceptance and consent of older test users might have affected by the way the mobile mental wellness training application was delivered for them. In the Circle of Friends group the researchers visited one of the sessions and introduced the study and the application for them. The observers saw that the group leaders had a significant effect on the test situation. They were already familiar to the participants and their positive attitudes seemed to make the process more fluent. Although the same group leaders introduced the study for the family caregivers, they did not have similar introductory session with researchers, which might explain their lower attendance (compared to the group size) to the study.

Acceptance barriers are associated with the thoughts and attitudes of a person. ${ }^{33}$ Based on the Circle of Friends observational study results, one could state that those who originally had negative attitudes towards new technological applications and test situations of this kind had difficulties getting rid of these feelings during the introductory session. One group member 
even refused to try the application at all. Furthermore, the participants were primarily interested in joining the group meeting although they knew that part of the associated time would be devoted to testing a technological application. Therefore, they constituted a sample in which not all participants were enthusiastic about trying out new technology.

The treatment protocol was different between the two groups due to different target groups with different needs and thus different content of the sessions. In addition, the Circle of Friends group included mindfulness exercises also in their activities forming an additional channel for learning mindfulness skills besides the application under study.

Patients ability to understand and perform intervention-related skills is referred to as receipt of treatment. ${ }^{32}$ Most of the older users were not familiar with mobile devices that had touchscreen user interfaces beforehand, and some of the participants had to focus on learning how to use the device before trying to use the application. Also, with older adults as target group, physical barriers, such as age-related cognitive, sensory, and motor decline or deficits, ${ }^{33}$ may have decreased their ability to begin performing the exercises. Although, this issue was taken into consideration by teaching mobile device use during several sessions, the physical barriers may have contributed to the fact that some of the participants found learning to use the device to be excessively laborious. The small screen size of the mobile device may have been one of the most crucial disadvantages in this study since the text on the screen could not be enlarged to compensate for reduced eyesight. This can also be seen as a technological design barrier ${ }^{33}$, since the device with a rather small screen and touch user interfaces, and the application itself, were not specifically designed for older users. The user interface and the content were not adapted for the target group in question. In the future, it 
would be interesting to conduct a similar study using a device with a larger screen, for instance, a tablet that older adults have previously adopted successfully. ${ }^{34}$

Evaluation of enactment of treatment involves the assessment of how test subjects perform treatment-related skills in relevant real-life settings. ${ }^{32}$ In this study, the enactment of mindfulness skills was monitored by collecting Oiva application usage logs. Between those who completed the study, the total usage time varied from less than six hours to more than 40 hours. Those who used the application more seemed also to like it more and gave, for example, higher overall ratings for the application. Although the group leaders expected the family caregivers to benefit from the skills that the application taught, it became evident that the latter were under a lot of stress and that it was difficult for them to find the time to use the application and to do the exercises. Possibly due to their lack of time and commitment, the overall ratings that the family caregivers gave were lower than those that the Circle of Friends group members gave. These particular user groups should be studied further to find out how to make technology solutions that can be integrated into their demanding circumstances and provide the help they need.

Ahtinen et al. ${ }^{19}$ used the AAQ-II instrument to measure mindfulness skills or psychological flexibility ${ }^{35}$ in their study. They found no clear improvement during a one-month trial. Similarly, none of the participants in this study had substantive changes in their FMI scores after three months of using the application. However, interestingly, the one test user who continued to use the application independently showed significant FMI score improvement during the independent-use period. The result is not generalizable as it is based on a single user. However, it indicates that improving mindfulness skills may require a longer period of practice. The results can be used to design a randomized controlled study with a larger test 
group to validate the effectiveness of technology-enhanced mental wellness group intervention for older adults.

Most of the participants considered the application exercises (the application content) to be useful and appreciated them. They were suitable for incorporation into group activities. The exercises had the capacity to give rise to very personal experiences, and sharing them required trust among the group participants. Thus, at the time of the introduction of the mindfulness exercises in the group, it was important for the group members to be comfortable and to know each other and the group leaders. The exercises required quiet space, a small enough group size, and the motivation, familiarity, and interest of the group leaders to achieve the group participants' engagement. However, there were challenges associated with adopting them for independent use between group sessions using the mobile application. The blended care approach, in which both technology and face-to-face modalities are applied, gives those who are unable to concentrate or are suffering from severe depression the opportunity to listen to the exercises or learn how to use the technology. Blended care is proposed as an effective and cost-effective way of organizing mental health care. ${ }^{36}$ In fact, the Circle of Friends group leaders have also continued applying suitable Oiva exercises in their group work after this study. They are currently accumulating additional experience for more comprehensive effectiveness evaluation.

\section{Conclusions}

This paper presents the results of an exploratory small-scale study, which investigated the feasibility of mobile technology in mental wellness training for older adults. Its strengths include the use of methodological triangulation, the involvement of real end users (including older adults and social care professionals), and the use of an application created on the basis 
of scientific knowledge regarding mental wellness training. The sample size and narrow demographics were limitations in this study. It reduces the generalizability of the results obtained although they serve as indicators of feasibility and the possible problems associated with implementing mental wellness training using a blended care model with mobile technology. When interpreting the results of this study, it should also be noted that the participants in the groups were exposed to simultaneous group intervention, which presumably affected the trial outcomes. The technical difficulties encountered hindered the thorough evaluation of the effectiveness of the mobile application since the target group did not fully adopt it. The mobile device selected significantly impacted the results; this was especially evident in the difficulties that the participants experienced while learning how to use the application. Furthermore, the selection of target groups presumably affected the high dropout rate among the participants. Learning and testing the application became too laborious in demanding life situations, for example, those of family caregivers. However, the results obtained in the study suggested that the concept of technology integrated into mental health group activity for older adults was promising provided that the special needs of the older users were taken into account in the selection of the devices and the design the applications. 


\section{References}

1. Barua A, Kar N, Ghosh M, Basilio M. Prevalence of depressive disorders in the elderly. Ann Saudi Med. 2011;31(6):620. doi:10.4103/0256-4947.87100.

2. WHO Mental health of older adults. WHO. http://www.who.int/mediacentre/factsheets/fs381/en/. Published 2017. Accessed December 19, 2017.

3. Wang J, Shang J, Kearney JA. Mental health disorders in home care elders: An integrative review. Geriatr Nurs (Minneap). 2016;37(1):44-60. doi:10.1016/j.gerinurse.2015.10.013.

4. Sotkanet. Sotkanet. https://www.sotkanet.fi/sotkanet/fi/taulukko/?indicator=s070ty40AgA=\&region=s07 $\mathrm{MBAA}=$ \&year=sy4rBQA=\&gender=t\&abs=f\&color=f. Published 2014. Accessed March 17, 2016.

5. Singh A, Misra N. Loneliness, depression and sociability in old age. Ind Psychiatry J. 2009;18(1):51-55. doi:10.4103/0972-6748.57861.

6. National Institute for Health and Welfare. Terveytemme/ATH. http://www.terveytemme.fi/ath/aikasarja20132015/raportti/atlas.html?select=1001\&data=ath_mentalht_lonely_cr. Published 2015. Accessed March 17, 2016.

7. Steptoe A, Deaton A, Stone AA. Subjective wellbeing, health, and ageing. Lancet. 2015;385(9968):640-648. doi:10.1016/S0140-6736(13)61489-0. 
8. Stiglitz JE, Sen A, Fitoussi J-P. Report by the Commission on the Measurement of $\begin{array}{lllll}\text { Economic Performance } & \text { and } & \end{array}$ http://www.insee.fr/fr/publications-et-services/dossiers_web/stiglitz/doccommission/RAPPORT_anglais.pdf.

9. Price M, Yuen EK, Goetter EM, et al. mHealth: A Mechanism to Deliver More Accessible, More Effective Mental Health Care. Clin Psychol Psychother. 2014;21(5):427-436. doi:10.1002/cpp.1855.

10. Chan S, Torous J, Hinton L, Yellowlees P. Mobile Tele-Mental Health: Increasing Applications and a Move to Hybrid Models of Care. Healthcare. 2014;2(2):220-233. doi:10.3390/healthcare2020220.

11. Harrison V, Proudfoot J, Wee PP, Parker G, Pavlovic DH, Manicavasagar V. Mobile mental health: Review of the emerging field and proof of concept study. J Ment Heal. 2011;20(6):509-524. doi:10.3109/09638237.2011.608746.

12. Donker T, Petrie K, Proudfoot J, Clarke J, Birch M-R, Christensen H. Smartphones for Smarter Delivery of Mental Health Programs: A Systematic Review. J Med Internet Res. 2013;15(11):e247. doi:10.2196/jmir.2791.

13. Aitken M, Lyle J. Patient Adoption of mHealth. Report by the IMS Institute for Healthcare Informatics.; 2015. http://www.imshealth.com/en/thoughtleadership/ims-institute/reports/patient-adoption-of-mhealth.

14. Silva PA, Holden K, Jordan P. Towards a List of Heuristics to Evaluate Smartphone Apps Targeted at Older Adults: A Study with Apps that Aim at Promoting Health and WellBeing. In: 2015 48th Hawaii International Conference on System Sciences. IEEE; 
2015:3237-3246. doi:10.1109/HICSS.2015.390.

15. Eurostat1.

$$
\text { Individuals }
$$

internet

use.

http://appsso.eurostat.ec.europa.eu/nui/show.do. Published 2015. Accessed March 17, 2016.

16. Eurostat2. Individuals using mobile devices to access the internet on the move. http://ec.europa.eu/eurostat/tgm/table.do?tab=table\&init=1\&plugin=1\&pcode=tin0 0083\&language=en. Published 2015. Accessed March 17, 2016.

17. Statistics Finland. Vanhojen ikäryhmien tieto- ja viestintätekniikan käyttö. http://www.stat.fi/til/sutivi/2013/sutivi_2013_2013-11-07_kat_002_fi.html. Published 2013. Accessed November 25, 2015.

18. Chittaro L, Vianello A. Mobile Mindfulness and User'sWorry: A Qualitative Study of Using a Smartphone App for Distancing from Negative Thoughts. Interact Comput. 2016. doi:10.1093/iwc/iwv044.

19. Ahtinen A, Mattila E, Välkkynen $P$, et al. Mobile mental wellness training for stress management: Feasibility and design implications based on a one-month field study. JMIR mHealth uHealth. 2013;15(7):1-13. doi:10.2196/mhealth.2596.

20. Plaza I, Demarzo MMP, Herrera-Mercadal P, García-Campayo J. Mindfulness-based mobile applications: literature review and analysis of current features. JMIR mHealth uHealth. 2013;1(2):e24. doi:10.2196/mhealth.2733.

21. Hayes SC, Luoma JB, Bond FW, Masuda A, Lillis J. Acceptance and Commitment Therapy: Model, processes and outcomes. Behav Res Ther. 2006;44(1):1-25. 
doi:10.1016/j.brat.2005.06.006.

22. Lappalainen $\mathrm{P}$, Langrial S, Oinas-Kukkonen $\mathrm{H}$, Tolvanen A, Lappalainen R. Web-Based Acceptance and Commitment Therapy for Depressive Symptoms With Minimal Support. Behav Modif. 2015;39(6):805-834. doi:10.1177/0145445515598142.

23. Riva G, Baños RM, Botella C, Wiederhold BK, Gaggioli A. Positive Technology: Using Interactive Technologies to Promote Positive Functioning. Cyberpsychology, Behav Soc Netw. 2012;15(2):69-77. doi:10.1089/cyber.2011.0139.

24. Becker S, Miron-Shatz T, Schumacher N, Krocza J, Diamantidis C, Albrecht U-V. mHealth 2.0: Experiences, Possibilities, and Perspectives. JMIR mHealth uHealth. 2014;2(2):e24. doi:10.2196/mhealth.3328.

25. Kaipainen K, Välkkynen P, Kilkku N. Applicability of acceptance and commitment therapy-based mobile app in depression nursing. Transl Behav Med. 2017;7(2):242253. doi:10.1007/s13142-016-0451-3.

26. Denzin NK. The Research Act: A Theoretical Introduction to Sociological Methods. 2d ed. New York: McGraw-Hill.; 1978.

27. Jansson A, Ylimaa T, Helin S, Pitkälä K. Circle of Friends - Group Model Alleviating Loneliness. In: IAGG-ER Dublin, Poster Presentation. Dublin; 2015.

28. Kurlowicz L, Greenberg SA. The Geriatric Depression Scale (GDS). Hartford Inst Geriatr Nursing, New York Univ Coll Nurs. 2007;(4).

29. Friedman B, Heisel MJ, Delavan RL. Psychometric properties of the 15-item geriatric depression scale in functionally impaired, cognitively intact, community-dwelling 
elderly primary care patients. J Am Geriatr Soc. 2005;53(9):1570-1576. doi:10.1111/j.1532-5415.2005.53461.x.

30. Bryman A. Social Research Methods. 4th Editio. Oxford, UK: Oxford University Press; 2012.

31. Walach $\mathrm{H}$, Buchheld $\mathrm{N}$, Buttenmüller $\mathrm{V}$, Kleinknecht $\mathrm{N}$, Schmidt S. Measuring mindfulness - the Freiburg Mindfulness Inventory (FMI). Pers Individ Dif. 2006;40(8):1543-1555. doi:10.1016/j.paid.2005.11.025.

32. Bellg AJ, Borrelli B, Resnick B, et al. Enhancing Treatment Fidelity in Health Behavior Change Studies: Best Practices and Recommendations From the NIH Behavior Change Consortium. Heal Psychol. 2004;23(5):443-451. doi:10.1037/0278-6133.23.5.443.

33. Fletcher J, Jensen R. Mobile health: Barriers to Mobile Phone Use in the Aging Population. Online J Nurs Informatics. 2015;19(3). http://www.himss.org/ResourceLibrary/GenResourceDetail.aspx?ItemNumber=4555 1.

34. Tsai HS, Shillair R, Cotten SR, Winstead V, Yost E. Getting Grandma Online: Are Tablets the Answer for Increasing Digital Inclusion for Older Adults in the U.S.? Educ Gerontol. 2015;41(10):695-709. doi:10.1080/03601277.2015.1048165.

35. Bond FW, Hayes SC, Baer RA, et al. Preliminary Psychometric Properties of the Acceptance and Action Questionnaire-II: A Revised Measure of Psychological Inflexibility and Experiential Avoidance. Behav Ther. 2011;42(4):676-688. doi:10.1016/j.beth.2011.03.007. 
36. Wentzel J, van der Vaart R, Bohlmeijer ET, van Gemert-Pijnen JEWC. Mixing Online and Face-to-Face Therapy: How to Benefit From Blended Care in Mental Health Care. JMIR Ment Heal. 2016;3(1):e9. doi:10.2196/mental.4534. 